\title{
Development of Possible Solution to Overcome Factors Influence on Sustainable Construction Process
}

\author{
Ryad Tuma Hazem ${ }^{a^{*}}$, Hatem Khaleefah Breesam ${ }^{\mathrm{b}}$ \\ ${ }^{a}$ Ph.D. Student, Civil Engineering Department, College of Engineering, University of Baghdad, Al-Jadriya, Baghdad, 10071, Iraq. \\ ${ }^{b}$ Assistant Professor, Civil Engineering Department, College of Engineering, University of Baghdad, Al-Jadriya, Baghdad, 10071, Iraq.
}

Received 26 February 2019; Accepted 01 June 2019

\begin{abstract}
The both of time challenges and technology developments are having influence on changes in the required level of any types of industries and in any country in the world. The importance of construction industry is making this sector need to develop without forgetting the negative impacts of the construction process on environment aspects. The objective of this paper is to identify the factors within negative impacts on sustainable process in construction industries by taking the vision of specialists via questionnaire techniques. The Identified factors has been divided into three groups each group associated with the concepts of integrated sustainable. The study is focused on "required actions" that have been drawn through experts to show the roadmap that will help the contractual parties to start in converting the traditional process on construction to be sustainable process. Through the conclusions can be reached facts that contribute to the adoption of sustainable standards in the construction industry in Iraq as a developing country.
\end{abstract}

Keywords: Construction; Factors; Influence; Sustainable; Project Management.

\section{Introduction}

For every system is needed the importance actions to develop all its parts. The stakeholders must spend more efforts to establish all sustainable concepts for implementation any construction project form conceptual phase until end step of project life cycle. There are so many factors influencing negative on establishment the sustainable criterions in construction process. Many studies have reflected the importance of sustainability in the construction industry. For developing a specific sustainable system in construction projects this requires continuous measures to minimize the side effects of the activities associated with this field. In order to achieve sustainable objectives, considerations should be given to the stages required to implement them and to prioritize the study of the reality of the challenges associated with each phase in order to reach the treatments on each part of problems during the implementation stages of the targeted system [1]. The design process has progressed to the stage when the construction activities can begin, certain issues that affect the sustainability of the finished product have been already fixed. The location, the building/structure's use and form, many of the specified materials, and who is going to undertake the construction will have already been decided. The location, the building/structure's use and form, many of the specified materials, and who is going to undertake the construction will have already been decided. If it can be assumed that all efforts that could have been made have been undertaken to ensure the final product is as sustainable as can be expected, these can still be undone in either major or minor ways by 'getting it wrong' on site and after the building is occupied [2].

\footnotetext{
* Corresponding author: ryadtuma@gmail.com 
International studies on the factors influencing the application of sustainability have given significant importance to these factors. Companies can do much to move towards more sustainable practices. Their efforts can be enhanced by developing an integrated business management system to manage economic, environmental and social issues. But although the guiding principles are in place, the question remains: What does sustainable development mean in practice for specific sectors of industry. To provide an insight into the way of addressing the sustainability challenge for the industry. It has been argued that the current contracting and bidding practices are unsustainable as they are focused on short-term economic gains with little consideration of environmental and social aspects. An alliancing approach in which partnerships are formed between the stakeholders in the contracting industry may help to move the sustainability agenda in the contracting industry further. However, this requires a close collaboration between contractors, clients, regulators and local communities [3]. The role of engineering teams within these partnerships is to demonstrate that it is possible to deliver more sustainable designs not only by using the available and well-established techniques but also by considering innovative solutions and approaches. One of the important indicators in this study was to reach the possible solutions that contribute to the application of the adoption in its broad form through the sustainable applications in construction industrial. This research is aim to identify several number of factors to reflect its negative impacts on sustainable associated with construction industrials and objectives as shown in the following points:

- Identify the most important factors that influence on sustainable concepts in construction process in southern of Iraq.

- Possibility to reach the required solutions namely in this research is "required solutions" to overcome the negative impact of the identified factors as in this study.

\section{Literature Review}

The literature review has been done through some studies that have focused on multiple factors as well as their effects on the implementation of sustainable models or adopting all pattern of sustainable in construction stages. There are so many effects came from the construction activities which affected on the environments. The building sustainability is a process of producing structures which create a balance between environmental, social and economic sustainability by using environment friendly and resource-efficient processes towards achieving set project objectives [4]. There are so many effects came from the construction activities which affected on the environments. The energy consumption, gas emissions and waste generation are effected on the environment and sequences of activities while its influence are very clear to everyone on construction workers and their health's. The currently widely adopted three pillars (Economic, Social, and Environmental) of sustainability were promulgated in the early 1990s's [5]. Such a three-pillar framework for the assessment of sustainability was adopted by most current national-level sustainability evaluation systems [6]. To reach to the best sustainable aspects and its application tat required to establishing of assessment indicators on environmental aspects [7].

About the design aspect The application of the generic eco-innovation model to develop a design alternative of a green roof that is eco-friendlier, more durable, and more cost-effective, compared with existing ones. A case study incorporating building information modeling technology and energy consumption analysis software was conducted to demonstrate the benefits of the innovative green roof proposed by the generic eco-innovation model [8]. For Conceptualization of an Indicator System for assessing the Sustainability of the Bioeconomy had been done and the focus of work on the design stages and their environmental and economic effects and reflected the importance of the application of sustainable standards [9]. Economic pillar: ensures financial affordability, employment creation, adopts full-cost accounting, and enhances competitiveness, sustainable supply chain management [10]. Environmental pillar comprises; waste management, prudent use of the four generic construction resources (water, energy, material and land), avoid environmental pollution... etc. Technical pillar includes, construct durable, functional, quality structure and etc. Some researchers stated that the philosophy of environmental sustainability is to leave the earth in as good or better shape for future generations [11-14].

Several researchers have presented some benefits of applying sustainable construction, including: shortened construction time, lower overall construction cost, improved quality, enhanced durability, better architectural appearance, enhanced occupational health and safety, material conservation, less construction site waste, less environmental emissions, and reduction of energy and water consumption [15, 16]. Akadiri an Olomolaiye [17] considered that the construction of buildings is a key negative factor of human impact on the environment. Landman [18-20] recognized a number of environmental, social, and economic benefits to be obtained from building more sustainably: (air and water quality protection; soil protection and flood prevention; solid waste reduction; energy and water conservation; climate stabilization; Ozone layer protection; natural resource conservation; and open space, habitat, and species/biodiversity protection). For researching of possible application that is required for Integrating Sustainability into Construction Engineering Projects that is important to take in consideration all aspects of sustainable in project planning [21]. 


\section{Research Methodology}

To reach the desired objectives of the search, it is necessary to design all steps of research correctly to ensure that the study meet with all objectives. Therefore, the research methodology steps as shown in the following main-points:

- Identity factors from previous studies and Literatures review.

- Categorize factors by adopting Focus Group Discussion "FGD".

- Preparation the form of questionnaire and then start next step of distribution of questionnaires for specialist engineering of (Civil, mechanical, Electrical and energy, Environmental engineering specialist, contracting and procurement specialist).

- Collecting of Questionnaire via personal, interviews and emailing system.

- Analysis of Questionnaire and obtaining ranking of each factors.

- Adopting the Required solutions by Interviews and FGD with specialization engineers and experts.

- Discussion and Recommendations.

Figure 1 shows the process of research during the period of study.

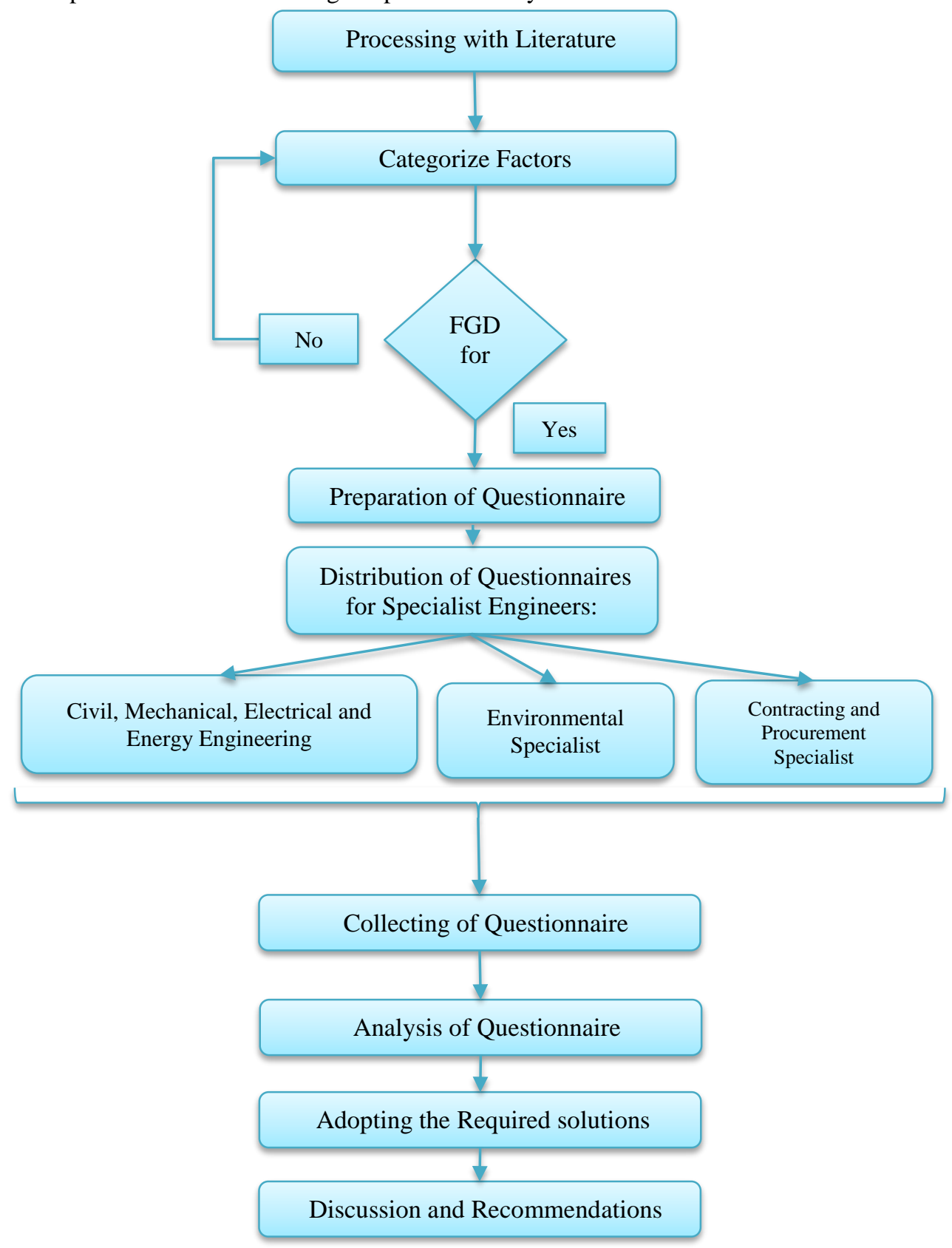

Figure 1. Process of Research 


\subsection{Design Questionnaire}

The closed questionnaire was designed to meet the needs of research's objectives and possible solutions related to the nature of research. After the administrative reviewed and approved the questionnaire. The questionnaire was styled in the following main sections. As in the following point show this details:

$1^{\text {st }}$ Sections: Personal Information about the targeted groups. And $2^{\text {nd }}$ Section: Impacts of the following factors on Sustainable of construction project: (The Impacts of the following factors on Connotation of Sustain within 17 factors, The Impacts of the following factors on Connotation of Care within 15 factors, The Impacts of the following factors on Connotation of Commitments within 15 factors). For purpose of the study is to apply on construction process, so data were collected through the staff of local construction firms. The identified local construction firms deal directly with the processes of construction, contracting and procurement procedures to ensure their employees have acceptable level and wide knowledge in all sustainable pillars. Therefore, the questionnaire was distributed to the targeted specialist groups from this identified firms to meet with criterion of samples.

\section{Categorize the Factors by Using Focus Group Discussion (FGD)}

The main reason behind this step is to categorize the list of those factor and then come back to experts to highlight the required action to improve the construction system to be on way of sustainable. Andrew Parker et al. [27] Adoption Focus Group Discussion techniques is one considers the contemporary use of focus groups as a method of data collection within qualitative in their papers. Based on David L. Morgan [28] the planning that must be done prior to doing focus groups. And that reflect how it is important to plan for the research work under FGD techniques. The experts had discussed as a group cycle in process of (FGD) within support of researcher as facilitator in process of FGD. Factors associated on connotation of Integrated Sustain "IS" \& Integrated Care "ICa" \& Integrated Commitments "IC" how to make the following terms from previous studies more sustain in integrated construction process. The following tables had been categorized via FGD process to display them in questionnaire.

Table 1. Showing Group one: Factors associated on connotation of Integrated Sustain "IS"

\begin{tabular}{|c|c|}
\hline Coding Factors according to SPSS & Factors - Integrated Sustain "IS" \\
\hline$I F-S 1$ & Sustaining of local employment opportunities \\
\hline$I F-S 2$ & Sustain and improve local infrastructure capacity \\
\hline$I F-S 3$ & Projects are providing community amenities \\
\hline$I F-S 4$ & Ecology preservation \\
\hline$I F-S 5$ & Sustain of Environmentally conscious design \\
\hline$I F-S 6$ & Modular and standardized design \\
\hline$I F-S 7$ & Sustain of Public awareness Recyclable/renewable contents \\
\hline$I F-S 8$ & Improve sustainable Industrial awareness Reusable/recyclable element \\
\hline$I F-S 9$ & Establishment accurate methods about disposing of chemical wastes \\
\hline$I F-S 10$ & Protect Water systems from any level of pollution \\
\hline$I F-S 11$ & $\begin{array}{l}\text { Provision of integrated plan for protection of flora, fauna, and } \\
\text { ecosystems from the processing of projects construction/operations }\end{array}$ \\
\hline$I F-S 12$ & Using of environment-friendly demolition methods \\
\hline$I F-S 13$ & Sustain on best methods of waste recycling and reuse \\
\hline$I F-S 14$ & Sustain on best methods Special waste treatment \\
\hline$I F-S 15$ & Conservation of biodiversity and environment \\
\hline$I F-S 16$ & sustain of natural resources efficiently \\
\hline$I F-S 17$ & Reduce greenhouse gases' emission \\
\hline
\end{tabular}


Table 2. Showing Group Two: Factors associated on connotation of Integrated Care "ICa"

\begin{tabular}{cl}
\hline $\begin{array}{c}\text { Coding Factors } \\
\text { according to SPSS }\end{array}$ & \multicolumn{1}{c}{ Factor- Integrated Care "ICa" } \\
\hline IF-Ca1 & Care of the project profitability associated with project grade, its level and the business wide locally \\
IF-Ca2 & Overcoming Infirmity of economic feeding and its benefits for domestic economics \\
IF-Ca3 & Care of capital budget, master planning, strategies of management of projects \\
IF-Ca4 & Programming of total cost controlling \\
IF-Ca5 & Overcoming of weakness in planning of current and future financial policies and financial styles \\
IF-Ca6 & Minimizing of randomized assessment the risks of fund sources for (mid and long )-terms \\
IF-Ca7 & Highly attention and consideration of life cycle cost \\
IF-Ca8 & Care in standard dimension in design specifications \\
IF-Ca9 & Care of materials choice \\
IF-Ca10 & Care of labour costs \\
IF-Ca11 & High considerations about materials costs \\
IF-Ca12 & High level of supervision of energy consumption \\
IF-Ca13 & High level of monitoring of water costs \\
IF-Ca14 & Training costs \\
IF-Ca15 & Waste disposal costs \\
\hline
\end{tabular}

Table 3. Showing Group Three: Factors associated on connotation of Integrated Commitments "IC"

\begin{tabular}{|c|c|}
\hline $\begin{array}{l}\text { Coding Factors } \\
\text { according to SPSS }\end{array}$ & Factors - Integrated Commitments “IC" \\
\hline IF-C1 & $\begin{array}{l}\text { Commitments about enhancing of local infrastructure capacities and its linkages: drainage, sewage, power, } \\
\text { road, and communication, transportation, dining, recreation, shopping, education, financing, and medical. }\end{array}$ \\
\hline IF-C2 & Commitment of workers' health safety assessment \\
\hline IF-C3 & Commitment air pollution assessment \\
\hline IF-C5 & Commitments on noise assessment \\
\hline IF-C6 & Commitments on waste generation assessments and its size \\
\hline IF-C7 & Commitments safety design criteria \\
\hline IF-C8 & Commitment of security considerations \\
\hline IF-C11 & Supporting of public awareness \\
\hline $\mathrm{IF}-\mathrm{C} 12$ & Commitment of all relevant legislations in sustainable issues \\
\hline IF-C13 & Provision of services during project life cycle \\
\hline IF-C14 & Commitments of all contractual parties in sustainable criterion \\
\hline IF-C15 & Commitments on continual improvement and innovation aspects \\
\hline
\end{tabular}

\section{Results and Discussion}

The next sections of this study shows details of results and how those the identified factors have gotten the ranks via participants in process of research. Also the other related sections deal with possible solutions form FGD process.

\subsection{Analysis of Questionnaires}

By depending on the questionnaire survey method to collect the responses in addition using email methods to give suitable time to participants to reply all the required questionnaires. The details of questionnaire are 1st -section about personal information, contact, positions, and experiences. 2nd-section is about the list of influence factors which divided into three groups based on experts' notion: $1^{\text {st }}$ group "Integrated Sustain" $2^{\text {nd }}$ group "Integrated Care" and $3^{\text {rd }}$ group "Integrated Commitments". Likert scale has been adopted for giving the participants an opportunity to choose in the form of survey which start from 1 to 5 to show the level of impact gradually: (1-not impact, 2-low impact, 3-mid impact, 
4-high impact and utmost impact as 5 highest in scale). Through chain-referral techniques from total 104 distributed questionnaires the 91 participants were conducted correctly within the form of survey correctly.

Table 4. Showing the details of participants "Functional Specialization" with certificate attitudes

\begin{tabular}{|c|c|c|c|c|c|c|c|c|c|c|}
\hline \multirow[b]{2}{*}{ \# } & \multirow[b]{2}{*}{ Functional Specialization in Department } & \multicolumn{8}{|c|}{ List of Participants within their certificate attitudes } & \multirow[b]{2}{*}{ Total } \\
\hline & & 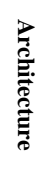 & : & $\begin{array}{l}\text { 몀 } \\
\frac{2}{2} \\
\frac{0}{2} \\
\frac{0}{8}\end{array}$ & 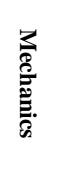 & 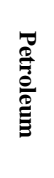 & 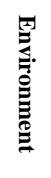 & 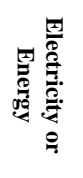 & 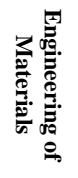 & \\
\hline 1 & Contracting Department & 1 & 6 & 0 & 1 & 1 & 2 & 0 & 1 & 12 \\
\hline 2 & Management\& construction & 1 & 9 & 1 & 1 & 1 & 1 & 0 & 1 & 15 \\
\hline 3 & Consultant/Designing & 6 & 2 & 1 & 2 & 0 & 1 & 1 & 0 & 13 \\
\hline 4 & Planning and Economic & 2 & 4 & 1 & 1 & 1 & 2 & 1 & 1 & 13 \\
\hline 5 & Academic & 1 & 4 & 1 & 1 & 2 & 1 & 0 & 1 & 11 \\
\hline 6 & Logistics Management & 1 & 4 & 1 & 1 & 1 & 2 & 2 & 2 & 14 \\
\hline \multirow[t]{2}{*}{7} & Safety and Environment management & 0 & 3 & 1 & 1 & 2 & 3 & 1 & 2 & 13 \\
\hline & & \multicolumn{8}{|c|}{ Total Distributed } & 91 \\
\hline
\end{tabular}

To find the top ranking of influence for each factor under its specific group that require to calculate all "means, standard deviation" for ranking those factors based on their weights. As shown in the Tables 5 to 7.

Table 5. Showing weights of nominated factor in pillar of Integrated Sustain

\begin{tabular}{|c|c|c|c|c|c|c|c|c|c|c|c|c|c|c|c|c|c|c|}
\hline \multicolumn{2}{|c|}{ Coding } & $\underset{0}{0}$ & 疍 & $\underset{\omega}{0}$ & $\begin{array}{l}7 \\
0 \\
1\end{array}$ & 昰 & 氛 & 氞 & 国 & $\overrightarrow{0}$ & $\begin{array}{l}\mathbf{7} \\
0 \\
0\end{array}$ & $\begin{array}{l}\mathbf{7} \\
\stackrel{0}{0} \\
=\end{array}$ & 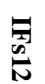 & 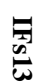 & 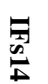 & 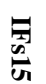 & $\begin{array}{l}\mathbf{7} \\
\hat{0} \\
\vdots\end{array}$ & $\begin{array}{l}\mathbf{t}_{2} \\
\stackrel{0}{3}\end{array}$ \\
\hline \multirow{2}{*}{$\mathrm{N}$} & 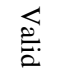 & 91 & 91 & 91 & 91 & 91 & 91 & 91 & 91 & 91 & 91 & 91 & 91 & 91 & 91 & 91 & 91 & 91 \\
\hline & 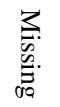 & 0 & 0 & 0 & 0 & 0 & 0 & 0 & 0 & 0 & 0 & 0 & 0 & 0 & 0 & 0 & 0 & 0 \\
\hline \multicolumn{2}{|c|}{ Mean } & $\stackrel{+}{\infty}$ & $\underset{\omega}{\omega}$ & $\underset{\perp}{\omega}$ & $\begin{array}{c}\omega \\
\dot{n} \\
\perp\end{array}$ & $\dot{\vec{N}}$ & $\begin{array}{l}w \\
\tilde{n}\end{array}$ & $\begin{array}{l}w \\
\infty \\
a\end{array}$ & $\omega_{\infty}^{\omega}$ & $\dot{w}_{a}^{w}$ & $\stackrel{\vec{N}}{+}$ & $\begin{array}{l}\omega \\
\infty \\
\infty \\
\infty\end{array}$ & $\dot{w}_{a}$ & $\stackrel{w}{i}$ & $\dot{u ̈ g}^{w}$ & $\underset{\omega}{\omega}$ & $\stackrel{w}{ \pm}$ & $\stackrel{+}{\sigma}$ \\
\hline \multicolumn{2}{|c|}{$\begin{array}{c}\text { Std. } \\
\text { Deviation }\end{array}$} & $\overline{u_{v}}$ & $\tilde{\tilde{\omega}}_{\tilde{u}}$ & $\bar{\omega}$ & $\underset{\circ}{\vec{b}}$ & $\overline{\dot{\phi}}$ & $\vec{w}_{w}^{\tilde{w}}$ & $\begin{array}{l}\vec{\omega} \\
t \\
\Delta\end{array}$ & $\overrightarrow{\vec{c}}$ & $\underset{\sim}{\tilde{N}}$ & $\begin{array}{l}0 \\
\infty \\
\infty \\
\infty\end{array}$ & $\check{\check{\phi}}$ & $\dot{8}$ & $\stackrel{\vec{A}}{a}$ & $\underset{\sim ్ \omega}{\tilde{\omega}}$ & 空 & $\overrightarrow{\tilde{u}_{0}}$ & $\stackrel{\circ}{\infty}$ \\
\hline
\end{tabular}

Table 6. Showing weights of nominated factor in pillar of Integrated Care

\begin{tabular}{|c|c|c|c|c|c|c|c|c|c|c|c|c|c|c|c|c|}
\hline \multicolumn{2}{|c|}{ Coding } & $\begin{array}{l}\text { 芳 } \\
\stackrel{0}{0}\end{array}$ & $\begin{array}{l}\text { F } \\
\text { 总 } \\
\text { : }\end{array}$ & $\begin{array}{l}\mathbf{F} \\
\text { 总 }\end{array}$ & 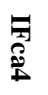 & $\begin{array}{l}\text { 极 } \\
\text { 预 }\end{array}$ & 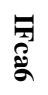 & \begin{tabular}{l} 
F \\
: \\
\multirow{3}{*}{}
\end{tabular} & 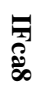 & $\begin{array}{l}\text { : } \\
\text { है } \\
\text { है }\end{array}$ & $\begin{array}{l}\text { 原 } \\
\stackrel{0}{6}\end{array}$ & $\stackrel{\overline{0}}{\overrightarrow{0}}$ & 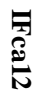 & $\stackrel{\overline{0}}{\tilde{\omega}}$ & $\stackrel{\overrightarrow{0}}{\tilde{C}}$ & $\begin{array}{l}\text { 胥 } \\
\stackrel{3}{6}\end{array}$ \\
\hline \multirow{2}{*}{$\mathrm{N}$} & $\begin{array}{l}\breve{\Xi} \\
\stackrel{0}{0}\end{array}$ & 91 & 91 & 91 & 91 & 91 & 91 & 91 & 91 & 91 & 91 & 91 & 91 & 91 & 91 & 91 \\
\hline & $\begin{array}{l}3 \\
3 \\
0.0 \\
0 \\
010\end{array}$ & 0 & 0 & 0 & 0 & 0 & 0 & 0 & 0 & 0 & 0 & 0 & 0 & 0 & 0 & 0 \\
\hline \multicolumn{2}{|c|}{ Mean } & $\stackrel{+}{i}$ & $\stackrel{N}{N}$ & $\omega$ & $\vec{\omega}$ & $\begin{array}{l}w \\
\dot{\omega}\end{array}$ & $\begin{array}{l}w \\
\dot{q}\end{array}$ & $\overrightarrow{0}$ & $\stackrel{N}{\infty}$ & $\stackrel{N}{\infty}$ & $\stackrel{N}{0}$ & w & $\underset{w}{w}$ & wo & 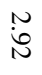 & \\
\hline \multicolumn{2}{|c|}{ Std. Deviation } & $\begin{array}{l}\stackrel{\circ}{\circ} \\
\stackrel{\circ}{0}\end{array}$ & i் & $\overline{\tilde{\sigma}}$ & $\begin{array}{l}\stackrel{P}{0} \\
\stackrel{\infty}{\omega}\end{array}$ & $\underset{\stackrel{i}{f}}{\vec{f}}$ & $\overrightarrow{\vec{\Delta}}$ & $\begin{array}{l}\vec{i} \\
\text { 㞻 }\end{array}$ & $\ddot{\omega}$ & $\underset{\substack{\infty \\
\perp}}{\vec{\perp}}$ & 芯 & $\overline{u_{u}}$ & 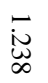 & $\overrightarrow{\tilde{\omega}}$ & $\overline{\tilde{\omega}}$ & $i_{\omega}^{\omega}$ \\
\hline
\end{tabular}


Table 7. Showing weights of nominated factor in pillar of Integrated Commitments

\begin{tabular}{|c|c|c|c|c|c|c|c|c|c|c|c|c|c|c|c|c|}
\hline \multicolumn{2}{|c|}{ Coding } & 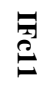 & $\overrightarrow{0}$ & $\begin{array}{l}\mathbf{7} \\
\hat{2}\end{array}$ & 胥 & $\overrightarrow{0}$ & $\begin{array}{l}\overline{0} \\
\hat{0}\end{array}$ & $\begin{array}{l}\overline{3} \\
\stackrel{3}{3}\end{array}$ & 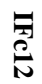 & 3 & $\begin{array}{l}\overline{0} \\
\stackrel{0}{0}\end{array}$ & $\stackrel{\nabla}{\varrho}$ & $\begin{array}{l}\overline{0} \\
\frac{2}{N}\end{array}$ & $\hat{0}_{\hat{\omega}}^{\mathbf{2}}$ & $\begin{array}{l}\mathbf{x}_{2} \\
\stackrel{2}{2}\end{array}$ & $\overline{0}_{\bar{n}}^{\bar{v}}$ \\
\hline \multirow{2}{*}{$\mathrm{N}$} & 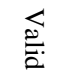 & 91 & 91 & 91 & 91 & 91 & 91 & 91 & 91 & 91 & 91 & 91 & 91 & 91 & 91 & 91 \\
\hline & 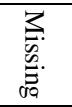 & 0 & 0 & 0 & 0 & 0 & 0 & 0 & 0 & 0 & 0 & 0 & 0 & 0 & 0 & 0 \\
\hline \multicolumn{2}{|c|}{ Mean } & $\begin{array}{l}\omega \\
\dot{\alpha}\end{array}$ & $\begin{array}{l}w \\
\dot{0}\end{array}$ & $\overrightarrow{\dot{\omega}}$ & $\ddot{u}_{u}^{u}$ & $\stackrel{\omega}{\omega}$ & $\stackrel{w}{\stackrel{w}{\sim}}$ & $\underset{\omega}{\omega}$ & $\begin{array}{c}N \\
\infty \\
+\infty\end{array}$ & $\overrightarrow{\dot{\omega}}$ & $\begin{array}{l}\omega \\
\stackrel{\vec{N}}{ }\end{array}$ & $\stackrel{\omega}{+}$ & $\begin{array}{l}\omega \\
\dot{\omega}\end{array}$ & $\underset{\sigma}{\omega}$ & $\begin{array}{l}\omega \\
\rightleftarrows\end{array}$ & $\stackrel{\vec{i}}{\vec{f}}$ \\
\hline \multicolumn{2}{|c|}{ Std. Deviation } & $\bar{i}$ & $\bar{i}$ & i & $\overrightarrow{\text { in }}$ & $\bar{\omega}$ & $\bar{\omega}$ & $\bar{\omega}$ & $\overrightarrow{i n}$ & i & $\bar{i}$ & $\overline{i_{n}}$ & $\bar{\omega}$ & $\vec{\perp}$ & $\bar{\perp}$ & $\bar{i}$ \\
\hline
\end{tabular}

\subsection{Possible Solutions}

To develop any model application logically as (engineering application model) that must find some solutions or treatments related to any application. In this part of the study is focused on access to solutions possible to specialists and experts. The solutions/treatment have been named in (Solutions/s required) base on the experts and specialist engineers. Through Focus Group Discussions (FGD) with (experts and specialist engineers) to reach on the required actions for the items (factors) and to focus on their influence level. The list of the possible required solutions which are associated with the problems that stand behind each factor and its impacts all of those actions will help the contractual parties to agree on establishing the first steps and give more attention for sustainable orientation during any process in construction sector. The Table 8 show the required solutions for sustainable orientation and overcome the negative influences of the studied factors.

Table 8. Showing Possible required solutions for the influences of the high ranking factors on Connotation of "Integrated Sustain"

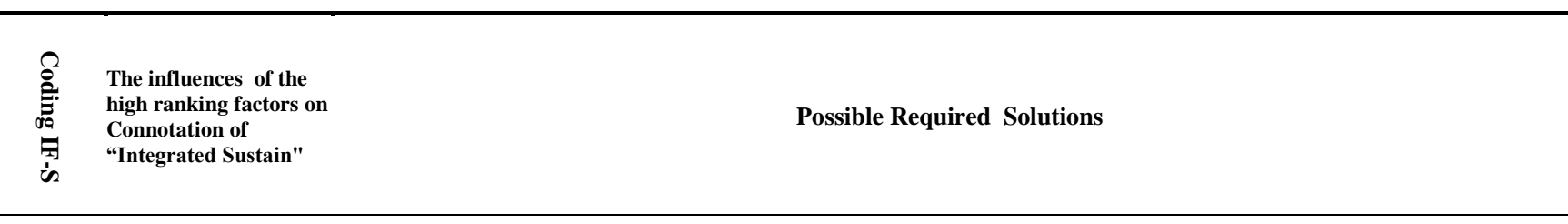

1) Develop appropriate legislation and regulations to begin the transition towards comprehensive sustainability

2) Contract terms must include sustainable standards

Sustaining of local 3) Emphasis on the inclusion of financial audits and the contracting of methods of sustainability in projects

IF-S1 employment

opportunities $\quad$ 4) Periodically Evaluate and tracking the numbers of employment from local communities in both level permanent and temporary or in other words long term contract and service contracts).

5) Develop an annual plan and compare it with plans designed to calculate the direct and indirect beneficiaries of the project according to clear accounting criteria

1)Adopt a methodology that includes sustainability criteria in bid analysis

2) scope of construction and services must include (Establish Project Management Philosophy and Project Management \& Master Execution Plan and to implement the same throughout the entire project phases and to be supported by effective PMC Organization which takes all roles and responsibilities to cover sustainable steps in project life cycle)

Sustain of $\quad 3$ )Develop a short, medium and long term plan for the purpose of selecting secondary contractors and contractors according to sustainable IF-S5 Environmentally standards

conscious design $\quad$ 4) A unique sustainable tendering style and concentrate on the scores and criteria most pertinent to whole client's requirements.

5) Availability of the environmental Impact Checklist

6) Stay away from the policy of choosing the lowest bids criterions and using of the policy of sustainable giving to contribute to spreading sustainable awareness of competing companies.

1) The project/its whole process must include brief description of project activities/events within scale of availability of water system around the project.

Protect Water

2) Availability of Checklist of potential impacts of the level of pollution on water system and its analysis within possible actions required to

$\begin{array}{ll}\text { IF-S10 } & \text { systems from any } \\ & \text { level of pollution }\end{array}$ protect water system

3) Protecting water system from construction contaminants and contaminants associated with the oil industry by using: precautionary measures during the project life cycle.

4) Availability of monitoring and evaluation system to pollution during life cycle of the project by using smart technologies and its applications measurements. 
1) Provide a monitoring and evaluation system for greenhouse gases' emission.

2) Develop appropriate plans to reduce the risks of gases emitted to workers in the project camps

IF-S17 Reduce greenhouse 3) Compliance with sustainable standards for gases emitted by construction and oil operations and the escalation of dust and other gases' emission contaminants under the name of polluted gases.

4) Adopting on consultant firms which have the initiatives to minify of environmental effects through main aspects such as greenhouse, water use and consumption of energy, construction wastes, and air /water pollution impacts.

Table 9. Showing Possible Required Solutions for the influences of the high ranking factors on Connotation of "Integrated Care"

The influences of the high
ranking factors on
Connotation of "Integrated

1) Compliance of client with green procurement laws and instructions.

Care of the project

2) Imposition of contractual procedures to suppliers, subcontractors, venders to increasing level of commitments in sustainable zprofitability associated procurements bases

IF-Ca1 with project grade, its level

3) Availability of plans associated risks of environment, social and economic with obligations and level of opportunities for the and the business wide locally

4) Adoption of hierarchy proceeding of sustainable profit in construction business and oil industrial aspects in projects as unique production, contractors within their employees, requirements clients, reputation of organization in field of works.

5) Taking in consideration the social values and impacts of unique products as part of long-term profits to retain as values of project objectives.

1) Develop appropriate applications and policies to control costs and ways to improve their management methods to ensure the reduction of whole costs aspects and retain for long-term sustainable profit growth.

IF-Ca4 programming of total cost $\quad$ 2) Preparing of a comprehensive framework for reviewing and tracking the cost of consumptions in system to put the useful and appropriate controlling techniques to reduce consumptions quantities in all operational systems and controlling on their costs during life span of facility.

3) Simulating the main objective of reducing facility's system consumption and harmonizing with main objectives for sustainable development in the industrial and construction sectors.

1) Building of monitoring system for costs during the project life cycle

Highly attention and

2) Establish cost evaluation programs during the construction period and continue to track these costs during the period of operation and cost of maintenance

IF-Ca7 consideration of life cycle 3) Increase awareness among project managers to give high attention on non-conventional aspects of sustainable mechanisms to reduce their cost

3) Increase awareness among project managers to give high attention on non-conve
impact to meet the requirements of sustainable economic realities for facilities.

4) Engaging actively in making appropriate decisions during the whole timing process of the project by using the techniques and smart programs for cost simulators during the specified time periods as well as their contribution to rise of quality and sustainable standards for specific facility.

Table 10. Showing Possible Required Solutions for the influences of the high ranking factors on Connotation of "Integrated Commitments"

The influences of the high
ranking factors on
Connotation of "Integrated
Commitments"

1) Increase credits on logistics activities committed to sustainability standards to be one of the main resource of economic development.

IF-C3 Commitment air pollution to encourage them to adoption of sustainable logistics features

$\begin{array}{ll}\text { assessment } & 3 \text { ) Adopting environmentally friendly practices and maximizing ways to preserve environment. }\end{array}$

4) Working on assigning of legislations and instructions that accompany the movement of sustainable development in the construction business.

1) Work to motivate companies to take a greater interest in the logistics department.

2) Completely compliance with environmental protection instructions.

3) Working on update and develop organizational structure to keep up with new online technologies which meet completely with new organizational departments.

Commitments energy

IF-C9 savings and its

4) Training top management and decision makers to adopt sustainable methodology and make them part of the company's traditions in consumptions the foreseeable future.

5) Maintain skilled employees and committed staff to contribute to the changing of the traditional system into the sustainable logistic system to be part of projects life cycle.

5) Maintain skilled employees and committed staff to contribute to the changing of the traditional system into the sustainable logistic system to be part of projects life cycle. 
1) Availability of long-term strategies continual improvement and updated action plans which match with innovation/creativity activities.

Commitments on

IF-C15 continual improvement and innovation aspects
2) Involve all employees in the ongoing development process

3) Provide adequate preventive measures to address organizational, administrative, technical and financial problems to minimize the risks involved

4) Adopt innovation methods and creative ideas in the design, planning whole the stages throughout each project life cycle.

5) Coordinating with research and development centres, universities and local/ international institutes to obtain all outcomes associated with sustainable solutions.

\subsection{Discussion of Results}

To understand the interconnection among the high ranked factors of the model that contributes to the converting of construction practices from their traditional position to the status of sustainable development, the following figure show the ingrate between three different connotations to reach to ingrate level of construction practices by using the possible solutions. The Figure 1 is illustrating how to convert the required system in construction business into sustainable based on three main pillars environment, social and economic impacts to be equivalent to three oriented pillars as highly (Sustain, care and commitments) to assist the manager to start their works to be on sustainable development lines.

Integrated Care: is focused on create economically sustainable pillar through applying of within Possible Solution associated with grading of project profitability, evaluation of project's performance via total cost controlling and granting of greatest orientations about life cycle cost.

.
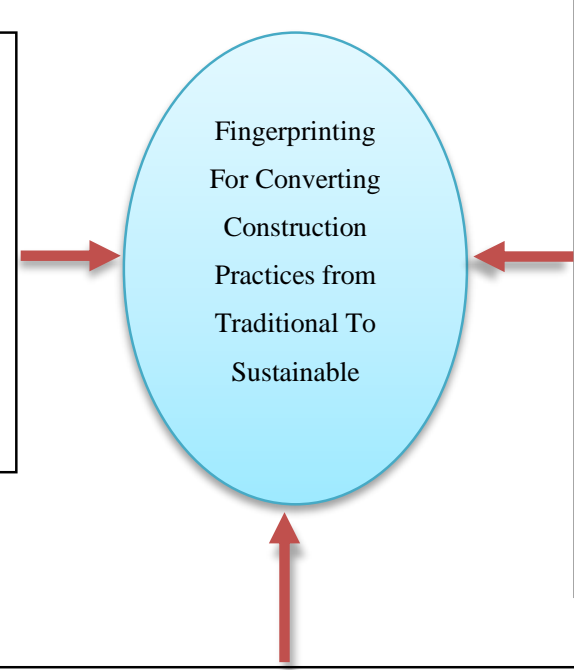

Integrated Sustain: is It relates to the methodology and interest in the social pillars and the importance of providing appropriate support to the surrounding community activities to obtain the social benefits form construction projects to reach to these objectives that required all possible solution associated with: Planning for maximizing of local employment opportunities, Match with mindful \& solicitous design environmentally, Protect Water systems from any level of pollution and decrease of greenhouse gases' emission.

Integrated Commitments: To ensure that the industrial and construction communities are willing to comply fully with sustainability standards and have a clear and explicit direction towards achieving their goals through applications and possible solutions associated with: Full Commitment in assessment pollution level in air, Full commitments in assessment of all applications and techniques of energy savings and its consumptions and Full commitments on continual improvement and innovation aspects.

\section{Figure 2. Styling for converting construction practices from traditional to sustainable}

\section{Conclusion}

The main objective of this paper is to categorize the factors under three pillars "sustain, care and commitments" and coverage the factors which have high weights through possible solution from very close experts to the construction situations to be the model very useful for contractual parties. The desire of the construction communities to move on real system and start a transition path towards the use of sustainable applications that also need full commitment to sustain construction project on sustainable visions to reach the greatest economic care for whole span life of any facility. During the decision making must to take in consideration (environment, social and economic impacts) and put the strategies shows policy commits in sustainable applications in construction process. The possible solutions are same as the green roads against each pillars to feed the contractual parties the actions to follow up their plan on sustainable road map in Iraq construction projects contexts.

\section{Conflict of Interest}

The authors declare no conflict of interest. 


\section{References}

[1] https://en.wikipedia.org/wiki/Sustainability. (Accessed on 1 May 2019).

[2] Goodhew, Steve. "Sustainable Construction Processes" (May 26, 2016). doi:10.1002/9781119247937.

[3] Nicholas, Michael J. “Towards Sustainable Process Contracting: The Case of the Glass Industry." Sustainable Development in Practice (January 28, 2005): 344-366. doi:10.1002/0470014202.

[4] Florez, Laura, Daniel Castro, and Javier Irizarry. "Measuring Sustainability Perceptions of Construction Materials." Edited by Mohammed Arif. Construction Innovation 13, no. 2 (April 12, 2013): 217-234. doi:10.1108/14714171311322174.

[5] Wikipedia, Brundtland Commission. Available online: https://en.wikipedia.org/wiki/Brundtland_Commission (Accessed on 1 January 2018).

[6] Huang, R.Y.; Hsu, W.T. On the Development of an appraisal indicator system for assessing the sustainability of construction engineering in Taiwan. In Proceedings of the 2007 Conference on Environmental, Taoyuan City, Taiwan, 14 December 2011; (In Chinese) Available online: http://www.tasder.org.tw/action.html (accessed on 10 May 2018). (In Chinese).

[7] Chen, Y.K. The Establishment of Assessment Indicators of Environmentally Sustainable Development and Its Application in Taiwan. Ph.D. Thesis, Department of Resource Engineering, National Cheng Kung University, Taiwan, 2007. (In Chinese).

[8] Yu, W.D., S.T. Cheng, C.M. Miao, and G.Y. Perng. "Green Innovation of Green Roof Technology - a Case Study." Materialwissenschaft Und Werkstofftechnik 48, no. 5 (May 2017): 420-429. doi:10.1002/mawe.201700015.

[9] Egenolf, Vincent, and Stefan Bringezu. "Conceptualization of an Indicator System for Assessing the Sustainability of the Bioeconomy." Sustainability 11, no. 2 (January 16, 2019): 443. doi:10.3390/su11020443.

[10] Hill, Richard C., and Paul A. Bowen. "Sustainable Construction: Principles and a Framework for Attainment." Construction Management and Economics 15, no. 3 (May 1997): 223-239. doi:10.1080/014461997372971.

[11] Bennett, J., and A. Crudgington. "Sustainable Development: Recent Thinking and Practice in the UK." Proceedings of the Institution of Civil Engineers - Engineering Sustainability 156, no. 1 (March 2003): 27-32. doi:10.1680/ensu.2003.156.1.27.

[12] Larsson, Nils. "Regionalism and Sustainable Development: Genesis of SB04." Building Research \& Information 33, no. 5 (September 2005): 397-404. doi:10.1080/09613210500219006.

[13] Zhang, Zhihui, Xing Wu, Xiaomin Yang, and Yimin Zhu. "BEPAS - a Life Cycle Building Environmental Performance Assessment Model.” Building and Environment 41, no. 5 (May 2006): 669-675. doi:10.1016/j.buildenv.2005.02.028.

[14] Zhang, Zhihui, Xing Wu, Xiaomin Yang, and Yimin Zhu. "BEPAS—a Life Cycle Building Environmental Performance Assessment Model.” Building and Environment 41, no. 5 (May 2006): 669-675. doi:10.1016/j.buildenv.2005.02.028.

[15] Jaillon, Lara, and C. S. Poon. "Sustainable Construction Aspects of Using Prefabrication in Dense Urban Environment: a Hong Kong Case Study." Construction Management and Economics 26, no. 9 (September 2008): 953-966. doi:10.1080/01446190802259043.

[16] Yu, Chuck W. F., and Jeong Tai Kim. "Building Environmental Assessment Schemes for Rating of IAQ in Sustainable Buildings." Edited by Jeong Tai Kim. Indoor and Built Environment 20, no. 1 (January 25, 2011): 5-15. doi:10.1177/1420326x10397780.

[17] Akadiri, Peter O., and Paul O. Olomolaiye. "Development of Sustainable Assessment Criteria for Building Materials Selection." Engineering, Construction and Architectural Management 19, no. 6 (November 9, 2012): 666-687. doi:10.1108/09699981211277568.

[18] Wimala, Mia, Emma Akmalah, and M. Rangga Sururi. "Breaking through the Barriers to Green Building Movement in Indonesia: Insights from Building Occupants.” Energy Procedia 100 (November 2016): 469-474. doi:10.1016/j.egypro.2016.10.204.

[19] Shi, Ge, Yuan, Wang, Kellett, Li, and Ba. “An Integrated Indicator System and Evaluation Model for Regional Sustainable Development.” Sustainability 11, no. 7 (April 11, 2019): 2183. doi:10.3390/su11072183.

[20] J.A. Bamgbade and A.M. Kamaruddeen and M.N.M. Nawi and A.Q. Adeleke and Maruf Gbadebo Salimon and W.A. Ajibike.M.N.M.1. "Analysis of some factors driving ecological sustainability in construction firms". Journal of Cleaner Production 10 no.3. (Jan 2019): 1537-1545. doi :10.1016/j.jclepro.2018.10.229.

[21] Miao Yu and Fangwei Zhu and Xiaotian Yang and Linzhuo Wang and Xiuxia Sun. "Integrating Sustainability into Construction Engineering Projects: Perspective of Sustainable Project Planning". Sustainability 10, no.3 (March 2018): 784.doi 10.3390/su10030784.

[22] Ewelina Kaatz, David Root, Paul Bowen. "Broadening project participation through a modified building sustainability assessment". Journal Article published in Building Research \& Information 33, no.5 (September 2005): 441 - 454. doi:10.1080/09613210500219113. 
[23] Li-Yin Shen and Jian Li Hao and Vivian Wing-Yan Tam and Hong Yao. "A Checklist for Assessing Sustainability Performance of Construction Projects". Journal of Civil Engineering and Management 13, No.4 (December 2007): 273-281. doi: $10.3846 / 13923730.2007 .9636447$.

[24] Naresh Kumar Agarwal.Verifying survey items for construct validity: "A two-stage sorting procedure for questionnaire design in information behavior research". American Society for Information Science and Technology 48, No. 1 (2011): 1-8. doi:10.1002/meet.2011.14504801166.

[25] Nannan Wang, Yen-Chiang Chang, Chris Nunn."Lifecycle assessment for sustainable design options of a commercial building in Shanghai". Building and Environment 45, On.6 (Jun 2010): 1415 -1421. doi.:10.1016/j.buildenv.2009.12.004.

[26] World Commission on Environment and Development- WCED (1987). The Brundtland Report,-pp.35.-Available_at: http://web.env.auckland.ac.nz/courses/geog320/resources/pdf/sustainability/Sneddon_et-al_2006.pdf (Accessed on March 2013).

[27] Richard C. Hill and Paul A. Bowen. "Sustainable construction: principles and a framework for attainment". Construction Management and Economics 15, no.3 (May 1997): 223 -239. doi :10.1080/014461997372971.

[28] Rajeev Ruparathna and Kasun Hewage. "Review of Contemporary Construction Procurement Practices". Journal of Management in Engineering 31, no.3 (May 2015): 0401-4038. doi: 10.1061/(asce)me.1943-5479.0000279.

[29] Amr Sourani and Muhammad Sohail. "Barriers to addressing sustainable construction in public procurement strategies". Proceedings of the Institution of Civil Engineers - Engineering Sustainability 164, no.4 (December 2011): 229—237. doi : 10.1680/ensu.2011.164.4.229.

[30] Chuck W. F. Yu and Jeong Tai Kim. "Building Environmental Assessment Schemes for Rating of \{IAQ\} in Sustainable Buildings". Indoor and Built Environment 20, no. 1 (Jan 2011), pp. 5-15. doi :10.1177/1420326x10397780.

[31] Ying Chen and Gül E. Okudan and David R. Riley. "Sustainable performance criteria for construction method selection in concrete buildings". Automation in Construction 19, no. 2 (March 2010): 235-244. doi:10.1016/j.autcon.2009.10.004.

[32] Riduan Yunus and Md. Asrul Nasid Masrom and Abd Hamid Abdullah and Fajaruddin Mustakim. "Conceptual Model of Contractor Satisfaction in the Industrialized Building System (IBS) Implementation”. Applied Mechanics and Materials 773774 (July 2015): 828 — 833. doi : 10.4028/www.scientific.net/amm.773-774.828.

[33] Riduan Yunus and Jay Yang. "Legislative Challenge to Sustainable Application of Industrialized Building System (IBS)”. Jurnal Teknologi 78, no.5 (April 2016). doi: 10.11113/jt.v78.8236.

[34] Sha Yu and Qing Tan and Meredydd Evans and Page Kyle and Linh Vu and Pralit L. Patel. "Improving building energy efficiency in India: State-level analysis of building energy efficiency policies". Energy Policy 110 (November 2017): 331-341. doi :10.1016/j.enpol.2017.07.013

[35] Jonathan Millar and Stephen Oliner and Daniel Sichel. "Time-To-Plan Lags for Commercial Construction Projects". National Bureau of Economic Research. (September 2013). doi :10.3386/w19408

[36] "Marine Environment Protection and Biodiversity Conservation" Springer Berlin Heidelberg, (2007). doi:10.1007/978-3-54037699-6.

[37] Liu, Guoxiang, ed. “Greenhouse Gases - Emission, Measurement and Management” (March 14, 2012). doi:10.5772/1797.

[38] S. Parkin and F. Sommer and S. Uren. "Sustainable development: understanding the concept and practical challenge". Engineering Sustainability 156, no.1 (March 2003): 19—26. doi:= 10.1680/ensu.156.1.19.37055.

[39] Bennett, J.; and Crudgington, A. "Sustainable development: recent thinking and practice in the UK". Engineering Sustainability 156, no.1 (March 2003):27 -32. doi:10.1680/ensu.156.1.27.37066.

[40] Du Plessis, C. "A strategic framework for sustainable construction in developing countries". Construction Management and Economics 1. 25, no. 1 (2007): 167-76. doi: 10.1080/01446190600601313.

[41] Alex Weaver, Jenny Pope, Angus Morrison-Saunders, Paul Lochner. "Contributing to sustainability as an environmental impact assessment practitioner”. Impact Assessment and Project Appraisal 26, no. 2 (Jun 2008): 91 to 98. doi:10.3152/146155108 x316423.

[42] Shamir Ghumra and Jacqui Glass and Matthew W. Frost and Miles Watkins and Jo Mundy. "Materials and energy assessment in Ceequal transport projects". Proceedings of the Institution of Civil Engineers - Transport 164, no.3 (August 2011): 153164. doi :10.1680/tran.2011.164.3.153.

[43] John C. Dernbach and Joel A. Mintz. "Environmental Laws and Sustainability: An Introduction”. Sustainability 3 no.3 (March 2011): 531-540. doi:10.3390/su3030531.

[44] Andrecka, Dr. Marta. "Innovation Partnership in the New Public Procurement Regime A Shift of Focus from Procedural to Contractual Issues?” SSRN Electronic Journal (2015). doi:10.2139/ssrn.2910911. 
[45] Andrew Parker \& Jonathan Tritter."Focus group method and methodology: current practice and recent debate". (23 Feb 2007). doi.:10.1080/01406720500537304.

[46] David L. Morgan. Focus Groups as Qualitative Research. Planning and Research. Design for Focus Groups. SAGE Research Methods. (1997): 32-46.doi: 10.4135/9781412984287.

[47] Chang, I.C. Application of Factor Analysis in Establishing the National Sustainable Development Evaluation. Indicator System for Taiwan. Ph.D. Thesis, Graduate Institute of Environmental Engineering, National Taiwan University, Taiwan, 2000. (In Chinese). 